\title{
Professional Development, Departmental Contexts, and Use of Instructional Strategies
}

\author{
Lisa R. Lattuca, ${ }^{a}$ Inger Bergom, ${ }^{a}$ and David B. Knight ${ }^{b}$ \\ a University of Michigan, ${ }^{b}$ Virginia Tech
}

\begin{abstract}
Background A report from the American Society for Engineering Education (Jamieson \& Lohmann, 2012) identified career-long professional development for faculty, teacher training in graduate programs, departmental climates that value and support educational innovation, and reward systems that recognize achievements in educational innovation as mechanisms to improve undergraduate engineering education. These factors have long been assumed to influence faculty members' choices to engage in educational improvements, but their relationships with teaching practices rarely have been studied.
\end{abstract}

Purpose We examined the relationships among professional development, departmental contexts, and engineering faculty members' use of student-centered teaching practices.

Design/Method This study drew on a nationally representative survey dataset of 906 engineering faculty members from 31 four-year institutions. We used multiple regression analyses to investigate whether graduate training, professional development, and institutional factors (e.g., reward systems) relate to engineering faculty members' use of studentcentered teaching practices, such as active learning and frequent and detailed feedback to students.

Results Professional development activities and, to a lesser extent, graduate training in teaching positively related to the use of student-centered teaching practices. We provide some of the first evidence that graduate training in teaching is linked to the use of studentcentered teaching practices. Only modest relationships were observed between departmental environments and teaching practices.

Conclusion Engineering departments seeking to increase the use of student-centered teaching practices should consider supporting faculty engagement in on- and off-campus professional development activities. Supporting these activities may be more effective than emphasizing research on engineering education and curriculum enhancement in reward decisions.

Keywords Classroom instruction; faculty development; organizational influences

\section{Introduction}

A recent report from the American Society for Engineering Education (Jamieson \& Lohmann, 2012) identified long-standing concerns regarding undergraduate engineering education in the United States, including "an ambitious, tightly sequenced, and highly technical 
curriculum; an imbalance in emphasis and integration of theory, practice, and how people learn; and a faculty reward system weighted heavily toward technical research and technology transfer" (Jamieson \& Lohmann, 2012, p. 2). Sheppard, Macatangay, Colby, and Sullivan (2009) noted that while undergraduate engineering curricula begin with foundational topics (e.g., science, mathematics) and progress to the senior capstone design experience, few students learn well through this linear progression that begins with theory and ends with unstructured design experiences. They wrote that in professional practice,

competence is manifested in the ability to read complex and ambiguous contexts and to carve out from them the important and productive problems that can then be addressed with precision through structured problem-solving techniques. Developing this capacity requires not a once-and-for-all movement from theory to application, but a continuing back-and-forth between general theoretical principles and the particularities of the problem situation as the student builds more sophisticated skills through experience. (p. 24)

Among the solutions offered in the ASEE report (Jamieson \& Lohmann, 2012) are careerlong professional development to ensure engineering faculty can develop and facilitate effective learning environments, teacher training in graduate programs, departmental climates that value and support educational innovation, and reward systems that recognize achievements in educational innovation. These factors have long been assumed to influence faculty members' choices to engage in educational improvements (e.g., Blackburn \& Lawrence, 1995), but their effects on teaching practices rarely have been studied.

In this study, we examined five hypotheses regarding the relationship between professional development, departmental contexts, and engineering faculty members' use of studentcentered teaching practices that are not commonly used in engineering courses. These hypotheses align with the study's conceptual framework, which is based on Blackburn and Lawrence's (1995) work on faculty motivation. Grounded in theory and research, Blackburn and Lawrence's conceptualization assumes that faculty members' interests, their self-assessments of their competencies, and their perceptions of what their departments value interact to shape their decisions about teaching (as well as research and service).

We focused on instructional practices such as active and collaborative learning and assessment methods using peer- and self-assessments of learning because they provide opportunities for engineering undergraduates to practice the kinds of skills they will need for engineering jobs, which are increasingly accomplished by teams of engineers and other professionals, often working in concert with clients and customers (ABET, 2013; National Academy of Engineering, 2004, 2005). This study offers insights into how personal and institutional factors may interact to shape instructional behaviors; it thus can inform future studies of pedagogical innovation in engineering and other academic fields.

\section{Instructional Choices}

Ample research supports the effectiveness of student-centered instructional and assessment practices, such as collaborative learning (e.g., Johnson, Johnson, \& Smith, 1998; Slavin, 1995) and frequent feedback to students (e.g., Bransford, Brown, \& Cocking, 1999; Huba \& Freed, 2000; Sorcinelli, 1991). Student-centered approaches to teaching are associated with greater student engagement and achievement than are traditional lecture-based, instructor-centered approaches (Prince, 2004). Faculty members' instructional choices, however, are strongly associated with their academic disciplines (Smart \& Ethington, 1995; Smart, Feldman, \& 
Ethington, 2000; Stark et al., 1990). Research indicates that instructors in so-called "hard" disciplines, such as engineering, are more likely to report using instructor-centered approaches than those in "soft" fields (Lindblom-Ylanne, Trigwell, Nevgi, \& Ashwin, 2006; Lueddeke, 2003; Nelson-Laird, Hu, Kuh, \& Schwarz, 2008; Prosser \& Trigwell, 1999; Trigwell, 2002). A survey of science, technology, engineering, and mathematics instructors found that lecturerecitation methods are still primarily used more often than student-centered techniques (Walczyk \& Ramsey, 2003); other research on postsecondary education in general showed similar findings (Dickie, Dedic, Rosenfield, Rosenfield, \& Simon, 2006; Lindholm, Szelényi, Hurtado, \& Korn, 2005; Schuster \& Finkelstein, 2006).

Evidence suggests, however, that engineering faculty members are increasing their use of active and collaborative teaching methods and are devoting time to learning about teaching more so than in the past (Lattuca, Terenzini, \& Volkwein, 2006). This increased interest in instructional and professional development is, in part, a reaction to a major shift in the accreditation standards for undergraduate engineering programs phased into effect in the late 1990s by the Accreditation Board for Engineering and Technology (ABET). In their study of the impact of the implementation of the accreditation criteria on U. S. engineering programs, Lattuca, Terenzini, and Volkwein (2006) examined the effects of the shift to this outcomes-based accreditation model in a nationally representative sample of more than 200 undergraduate engineering programs in 40 institutions. The study's conceptual framework assumed that to meet the new accreditation standards, engineering programs would have to revise their curricula and instructional practices to be aligned with the 11 specified learning outcomes. It further assumed that changes in the faculty culture would occur as faculty members engaged in activities such as outcomes assessment, curriculum revision, and professional development related to teaching and learning at a higher rate than before implementation of the new accreditation standards. As presumed, Lattuca et al. found that engineering program chairs and faculty members reported that they were aligning their courses and programs with the 11 learning outcomes specified in the accreditation standards; in particular, there was an increased emphasis on several of the mandated professional skills in courses and in programs overall. For example, to develop students' skill levels in engineering design, teamwork, and communication, engineering faculty respondents said they had increased their use of active learning methods. Half to two-thirds of these respondents said they increased their use of active learning approaches "some" or "significantly." They also reported that they relied less on lecturing and textbook problems in at least one of the courses they regularly taught (Lattuca et al., 2006).

Professional development activities also increased after the implementation of the new ABET accreditation standards. More than two-thirds of engineering faculty reported that, compared with seven to 10 years ago, they were reading more about teaching. About half reported more frequent involvement in professional development activities, such as workshops on teaching, learning, and assessment and projects to improve engineering education. Depending on the activity, one-fifth to one-quarter of faculty members said they had increased their teaching-and-learning-related professional development efforts in the past five years (Lattuca et al., 2006).

Engineering faculty members' choices of instructional strategies are subject to many influences, both internal and external to higher education institutions. For this reason, Lattuca et al. (2006) also examined the relationships between a dozen potential internal and external influences and the instructional changes that faculty reported making in their engineering 
courses; they found that faculty respondents viewed accreditation, industry feedback, and research on engineering education as significant, independent influences on their increased use of active learning techniques in courses they regularly taught. Faculty respondents also credited the changes they made in their courses to their own initiatives. Given their focus on accreditation, Lattuca et al. did not examine many other potential influences on faculty members' instructional and assessment choices that research and theory suggest may be at work. In this article, we explore additional potential influences on engineering faculty members' instructional choices. Specifically, we focus on the relationships among faculty members' participation in teaching-related professional development (both during graduate study and after), their perceptions of faculty reward systems, and their use of different teaching strategies.

\section{Professional Development}

College and university faculty tend to be underprepared for the instructional roles they assume (Golde \& Dore, 2001; Tanner \& Allen, 2006). Few feel they are adequately prepared to teach during their graduate studies, even if they are employed as teaching assistants (Golde \& Dore, 2001). Focusing specifically on engineering faculty, Ambrose and Norman (2006) noted,

When engineering faculty members enter the academy, many-through no fault of their own-are not fully prepared for their role as educators. Although graduate schools have begun to focus more attention on developing teaching skills, the main focus continues to be on creating researchers. As a result, when most faculty members enter the academy, they are, as Kuh et al. (2005) note, "well intentioned gifted amateurs" when it comes to teaching. (p. 25)

Although graduate programs, in general, do not prepare students well for the realities they face once they obtain a faculty position (Austin, 2002; Austin \& Wulff, 2004), students in the life sciences and engineering fields are less satisfied than are students in other fields with their preparation to teach (National Association of Graduate-Professional Students, 2001). Substantiating this claim using data from the study by Lattuca et al. (2006), Lattuca, Yin, and McHale (2010) found that only 15\% of engineering faculty had attended a program on how to teach when they were graduate students, only $6 \%$ had taken a course in college teaching, and only $1 \%$ had completed a teaching certificate during their graduate programs. Huang, Yellin, and Turns (2005) found that engineering faculty were concerned about their preparation for their teaching role; only $42 \%$ felt that their teaching experiences adequately prepared them for an academic or teaching career. This lack of preparation may, in part, explain why a large proportion of engineering faculty nationally reported attending a seminar on teaching and learning to help improve their teaching (Lattuca et al., 2006).

Programs that orient graduate students to faculty roles often focus attention on teaching. Although short orientation programs for new teaching assistants are likely to emphasize the standard procedures for classroom management and grading, more extensive programs such as those modeled after the Preparing Future Faculty programs developed in the 1990s have become increasingly common on university campuses. Many teaching and learning centers now offer seminars or credit-bearing courses in college teaching; in some universities, graduate students may opt to complete a certificate program on teaching. These programs purposefully introduce future faculty members to teaching strategies that stress student-centered practices. There is, however, little systematic study of the effects of such programs, which 
vary in content and duration from institution to institution. In one study of graduate teaching assistants' experiences in three science programs in a doctoral university, Luft, Kurdziel, Roehrig, and Turner (2004) found that most students considered their university's teaching orientation program too general to meet their instructional needs and reported they received limited departmental support. As a result, these graduate teaching assistants worked autonomously and often relied on their intuition and peers rather than on evidence-based teaching practices when teaching in their lab settings. Research suggests that successful programs for graduate teaching assistants stress the importance of pedagogy in promoting student learning (e.g., Hammrich, 1996, 2001; Ishikawa et al., 2000), offer discipline-specific instruction to support graduate teaching assistants' development and success (Hammrich, 2001; Pfund et al., 2009), and provide follow-up support (Pinder-Grover, 2013).

Although the evidence on the impact of graduate assistant programs on student-centered teaching practices is mixed and often based on small-scale studies and evaluations of specific programs, a few studies suggest that well-designed programs can have beneficial effects on teaching methods. Thus, our first hypothesis assumes that participation in programs on teaching at the graduate level positively relates to faculty members' choices of innovative instructional techniques and negatively relates to the use of lecture as a predominant teaching approach:

$\mathrm{H}_{1}$ : Graduate student training in teaching positively relates to the use of studentcentered teaching methods and negatively relates to the use of instructor-centered practices.

We explored a second hypothesis regarding the role of faculty professional development on instructors' pedagogical choices. Such programs often stress the use of student-centered teaching strategies, such as active and collaborative learning, to improve student learning and the use of student-centered assessment practices (Connelly \& Millar, 2006; Pfund et al., 2009). For many years, engineering faculty members have enrolled in three-day teaching workshops run by the National Effective Teaching Institute (NETI). In an evaluation of the influence of the NETI workshops on participating faculty, Felder and Brent (2010) indicated that many participants reported incorporating what they had learned at the NETI workshops into their teaching; these faculty members credited the experience with a moderate or strong influence on their decisions to do so. Similarly, in their evaluation of the impact of professional development programs on faculty members' teaching practices, Felder, Brent, and Prince (2011) showed that significant numbers of attendees reported that their teaching had improved and that they had adopted student-centered teaching practices. On the basis of evidence of the effect of such professional development activities on the teaching practices of engineering faculty, we hypothesized that

$\mathrm{H}_{2}$ : Professional development for teaching positively relates to the use of studentcentered teaching methods and negatively relates to the use of instructor-centered teaching practices.

\section{Effect of Departmental Context}

One measure of the interest in improving engineering education is the growing number of publication and presentation outlets for research on engineering education. Another is the rise of $\mathrm{Ph} . \mathrm{D}$. programs in engineering education that seek to encourage research on undergraduate and graduate education. Although engineering education departments have been created at large 
engineering schools, such as Purdue and Virginia Tech, it remains to be seen how research on engineering education will be evaluated for promotion and tenure in traditional engineering departments organized by discipline. Empirical evidence shows these systems have historically favored research activity over teaching, even in teaching-oriented colleges and universities (Fairweather, 1996). Jamieson and Lohmann (2012) argued that educational innovation in engineering requires the development of a supportive faculty culture in which faculty recruitment, hiring criteria and standards, and reward structures look beyond teaching excellence to consider explicitly faculty members' achievements in educational innovation in promotion and tenure criteria, processes, and practices. This claim aligns with Blackburn and Lawrence's (1995) conceptualization of faculty motivation, which stresses the interaction of individual and organizational features - faculty members rely not only on self-assessments in making choices about research, teaching, and service activities to pursue, but also on their understandings of their institution's values and reward system. We thus submit three additional hypotheses related to faculty perceptions of what their academic departments value:

$\mathrm{H}_{3}$ : Faculty members who perceive research (relative to teaching) to be an important factor in faculty hiring and rewards decisions in their departments are less likely to use student-centered teaching practices and more likely to use instructor-centered methods.

$\mathrm{H}_{4}$ : Faculty members who perceive engineering education research to be an important factor in rewards decisions in their departments are more likely to use studentcentered teaching practices and less likely to use instructor-centered methods.

$\mathrm{H}_{5}$ : Faculty members who perceive curriculum enbancement activities to be an important factor in faculty rewards decisions in their departments are more likely to use student-centered teaching practices and less likely to use instructor-centered methods.

\section{Conceptual Framework}

Our five hypotheses are consistent with the conceptualization of faculty motivation that emerged from Blackburn and Lawrence's (1995) examination of faculty work. Their research indicates that faculty members act on the basis of their own interests, their self-assessments of their competencies, and their perceptions of what their departments value. We assumed that engineering faculty engaging in professional development to improve their teaching are expressing both an interest in enhancing their pedagogical knowledge and skills and an assessment of their current competencies. Following Blackburn and Lawrence, we further assume that faculty members' social knowledge of what their departments value also shapes their teaching, research, and service behaviors. We are cognizant, however, of the conclusion that O'Meara, Terosky, and Neumann (2008) drew from their review of the literature on the influence of rewards on faculty behavior. Like Blackburn and Lawrence, O'Meara and her colleagues acknowledged the importance of the interactions of individual and institutional influences but argued that studies of faculty behaviors have been dominated by a "narrative of constraint" that focuses attention on structural and cultural barriers in the academic workplace that prevent faculty from engaging in particular kinds of work (p. 155). They suggest an alternative framing that views faculty as "central players in the design of the developmental supports they themselves require to grow as individuals, scholars, teachers, and members of multiple communities" (p. 165). Our analysis thus considered how both individual-level and contextual factors might relate to faculty members' decisions about teaching strategies. 


\section{Methods}

\section{Design, Population, and Sample}

Our goal in this study was to provide greater understanding of how individual and contextual factors relate to engineering faculty members' choices of teaching strategies. We used faculty data from a nationally representative dataset developed for the NSF-sponsored research project, Prototype to Production: Conditions and Processes for Educating the Engineer of 2020 (NSF DUE-0618712). The Prototype to Production study investigated the organizational conditions, policies and practices, and student experiences supporting the development of a variety of student learning outcomes by collecting data from engineering faculty, administrators, students, and alumni in 31 four-year institutions. Twenty-three of these institutions were selected using a disproportionate, $6 \times 3 \times 2$ stratified random sample that was drawn using the following strata: six engineering disciplines (biomedical/bioengineering, chemical, civil, electrical, industrial, and mechanical), three levels of highest degree offered (bachelor's, master's, and doctorate), and two levels of institutional control (public and private). To this sample, we added five case-study institutions that were participants in a companion qualitative study. One of the case-study institutions only offers a general engineering degree, so three institutions that offer general engineering degrees were included in the sample to serve as comparison institutions for a total of seven disciplines (biomedical/bioengineering, chemical, civil, electrical, general, industrial, and mechanical). Together, these seven disciplines accounted for $70 \%$ of all baccalaureate engineering degrees awarded in 2008 . This sampling design ensured that institutions in the final sample are representative of the population with respect to type, mission, and highest degree offered.

A university survey research organization handled data collection through a web-based questionnaire. Of the 2,942 faculty surveys sent, 1,119 were returned for a response rate of $38 \%$. For this article, we omitted survey responses from non-tenure-track faculty (132 of the total 1,119 faculty respondents) because these faculty members typically engage in different professional development opportunities and have different reward structures and criteria than do their tenured and tenure-track colleagues (Baldwin \& Chronister, 2001). We also omitted from our analyses cases in which the faculty respondent reported on a stand-alone laboratory course $(n=27)$ because this type of course typically calls for different instructional and assessment methods than those used in non-laboratory courses. Additionally, we omitted 54 faculty members from analysis because they had not taught an undergraduate course in the last five years. These omissions left a sample of 906 tenure-track or tenured engineering faculty members (see Table 1) who reported teaching the following kinds of courses: first-year or capstone design; fundamental math, science, or engineering science; engineering elective; or required engineering course.

Responses were weighted and adjusted by the response rate of institutions and by gender, discipline, race/ethnicity, and faculty rank within an institution. Missing data were imputed on the basis of procedures recommended by Dempster, Laird, and Rubin (1977) and Graham (2009) using the expectation-maximization algorithm of the Statistical Package for the Social Sciences (SPSS) software (v.18). To reduce data from several survey questions into fewer scales, a principal axis analysis (oblimin with Kaiser normalization rotation) was completed. Items were assigned to a scale on the basis of the magnitude of the factor loading, the effect of including an item on the scale's internal consistency reliability, and the researchers' professional judgment. Scales were formed by taking the sum of respondents' 
Table 1 Descriptive Statistics of

Faculty Respondents $(N=906)$

\begin{tabular}{|c|c|}
\hline Variable & Mean/Proportion ${ }^{a}$ \\
\hline $\begin{array}{l}\text { Institution type (by highest } \\
\text { degree offered) }\end{array}$ & $\begin{array}{l}81 \% \text { doctoral } \\
12 \% \text { master's } \\
6 \% \text { bachelor's }\end{array}$ \\
\hline Gender & $\begin{array}{l}85 \% \text { male } \\
15 \% \text { female }\end{array}$ \\
\hline Race/Ethnicity & $\begin{array}{l}\text { 55\% white } \\
\text { 14\% naturalized U.S. citizen } \\
\text { 13\% foreign national } \\
\text { 9\% Asian American } \\
\text { 4\% underrepresented minority } \\
5 \% \text { other }\end{array}$ \\
\hline Engineering department & $\begin{array}{l}45 \% \text { electrical } \\
17 \% \text { civil } \\
11 \% \text { chemical } \\
7 \% \text { mechanical } \\
20 \% \text { other }\end{array}$ \\
\hline Tenure status & $\begin{array}{l}71 \% \text { tenured } \\
29 \% \text { tenure-track, not tenured }\end{array}$ \\
\hline Faculty rank & $\begin{array}{l}46 \% \text { full professor } \\
28 \% \text { associate professor } \\
25 \% \text { assistant professor }\end{array}$ \\
\hline Class size of course taught most often & $\begin{array}{l}56 \text { students (average) } \\
\min =5, \max =1,400\end{array}$ \\
\hline Course type taught most often & $\begin{array}{l}90 \% \text { teach fundamental science or math course } \\
\text { or required or elective engineering course; } 10 \% \\
\text { teach first-year or capstone design course }\end{array}$ \\
\hline
\end{tabular}

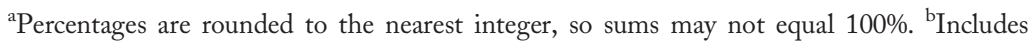
African American, Hispanic or Latino/a, and Native American.

scores on the items on a factor and dividing by the number of items in the scale as prescribed by Armor (1974).

\section{Variables}

We used three types of variables in this study: control variables, independent variables representing factors thought to influence the use of student-centered pedagogies, and dependent variables that are measures of the use of particular teaching practices.

Control variables In each analysis, we controlled for several variables (see Table 1). Institution type was coded into three categories, defined by highest degree offered (bachelor's, master's, and doctoral). Most faculty members in our sample are from doctoral institutions (737), and fewer represent master's and bachelor's institutions (113 and 56, respectively). We also controlled for specific characteristics of faculty members, including their gender, tenure status (tenured or tenure-track), rank (assistant, associate, full), race/ethnicity, and discipline (electrical, civil, chemical, mechanical, other) to isolate the relationship between professional 
Table 2 Descriptive Statistics of Independent

Variable Survey Items and Scales

\begin{tabular}{|c|c|c|}
\hline \multirow[b]{2}{*}{ Independent variables } & \multicolumn{2}{|c|}{$\begin{array}{l}\text { All faculty } \\
(N=906)\end{array}$} \\
\hline & $M$ & $S D$ \\
\hline $\begin{array}{l}\text { Graduate student training in teaching } \\
\text { Had formal teacher training before becoming faculty }\end{array}$ & $21.9 \%$ & - \\
\hline $\begin{array}{l}\text { Professional development for teaching activities in the past } 12 \text { months } \\
\text { Took a class or worked in industry to enhance knowledge or skills } \\
\text { Attended engineering education conference } \\
\text { Made a significant effort to improve teaching or course } \\
\text { Attended a workshop on teaching, learning, or assessment } \\
\text { Read journals or books on teaching, learning, or assessment } \\
\text { Wrote a paper, article, or chapter on teaching, curriculum, } \\
\text { or assessment }\end{array}$ & $\begin{array}{l}29.9 \% \\
14.8 \% \\
69.1 \% \\
36.5 \% \\
46.4 \% \\
19.7 \%\end{array}$ & $\begin{array}{l}- \\
- \\
- \\
- \\
-\end{array}$ \\
\hline $\begin{array}{l}\text { Time spent on research } \\
\text { Hours spent on research per week }\end{array}$ & 24.6 & 15.9 \\
\hline $\begin{array}{l}\text { Weight given to research (relative to teaching) } \\
\text { In hiring decisions } \\
\text { In promotion and tenure decisions } \\
\text { In merit salary decision }\end{array}$ & $\begin{array}{l}5.13 \\
5.17 \\
5.30\end{array}$ & $\begin{array}{l}1.81 \\
1.50 \\
1.60\end{array}$ \\
\hline $\begin{array}{l}\text { Weight given to engineering education research } \\
\text { In promotion and tenure } \\
\text { In merit salary scale }\end{array}$ & $\begin{array}{l}2.77 \\
2.66\end{array}$ & $\begin{array}{l}0.86 \\
0.86\end{array}$ \\
\hline $\begin{array}{l}\text { Weight given to curriculum enhancement } \\
\text { In promotion and tenure } \\
\text { In merit salary }\end{array}$ & $\begin{array}{l}2.94 \\
2.73\end{array}$ & $\begin{array}{l}0.74 \\
0.82\end{array}$ \\
\hline
\end{tabular}

Note. Means are for continuous variables, and percentages of faculty members indicating participation in an activity are shown for binary variables.

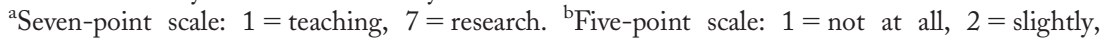
$3=$ moderately, $4=$ a good deal, $5=$ a great deal .

development and departmental factors and instructional choices. We also included as controls two variables that describe the specific course on which faculty members reported: class size and course type. The class size reported by our sample ranged from five to 1,400 students, and the average class size was 56 students. Controls for course type include design courses and all other courses (fundamental, required, elective).

Independent variables With two exceptions, graduate student training in teaching and time spent on research, the independent variables in the model, the independent variables included in the models represent empirically derived factors (see Table 2 for descriptive statistics). Each of these variables maps onto one of the five hypotheses. For graduate student training in teaching $\left(\mathrm{H}_{1}\right)$, we used a survey item asking respondents to indicate the teacher training activities in which they participated during graduate school, if any. We coded it as a binary variable, where 0 represents no formal training and 1 represents an experience in at least one of the following: attended a program for graduate students on how to teach $(17 \%$ of our sample participated in this experience), took course(s) in college teaching ( $7 \%$ of our sample), or completed a teaching certificate during a graduate program ( $2 \%$ of our sample). 
The small percentages of faculty members who engaged in each of these experiences precluded treating each type of experience individually. Professional development for teaching $\left(\mathrm{H}_{2}\right)$ is an independent variable represented in the model by six separate survey items. All six items were entered into regression models as variables so that we could identify the magnitude of the relationship between each professional development activity and the pedagogical decision variables.

Research orientation (relative to teaching) $\left(\mathrm{H}_{3}\right)$ is represented by four variables. First, we asked faculty members to report their time spent on research by indicating the number of hours they spent each week on research. This variable assesses the individual faculty member's current orientation toward research. We also asked faculty members to report on the perceived weight given to research versus teaching in their department in hiring decisions, merit salary decisions, and promotion and tenure decisions. For each of these items, faculty members responded on seven-item scales, where $1=$ teaching and $7=$ research. This variable represents the department orientation toward teaching versus research.

The final sets of independent variables related to the perceived weight given to engineering education research $\left(\mathrm{H}_{4}\right)$ and curriculum enhancement activities $\left(\mathrm{H}_{5}\right)$ in faculty rewards. Both are scale variables (ranging from 1 to 5 ) that emerged from a factor analysis of several survey items. Table 3 lists the survey items that compose each of these scales, as well as the Cronbach alpha statistic that indicates a measure of internal consistency for how closely the items relate as a group. Faculty members reported on the perceived emphasis placed on engineering education research and curriculum enhancement in decisions for both promotion and tenure and merit salary; both decision types are included as variables.

Dependent Variables We examined five dependent variables in our analyses (see Table 4 for descriptive statistics), using measures of how often faculty members reported using particular teaching and assessment approaches. Two of the student-centered teaching practices variables were scale variables that emerged from a factor analysis of several survey items (activity-based learning; instructor-centered assessment; see Table 5 for component items and internal consistencies), and one dependent variable was a single survey item (lecture). Faculty members

Table 3 Independent Variable Scales with Item Components

\footnotetext{
Engineering education research scale ${ }^{\mathrm{a}}$ In general, how much do the following "count" in annual merit salary and promotion and tenure reviews in your department?

Engineering education research publications

Engineering education conference publications

Engineering education research grants

Curriculum enhancement scale ${ }^{\mathrm{b}}$

In general, how much do the following "count" in annual merit salary and promotion and tenure reviews in your department?

Curriculum or course development

Writing textbooks

Writing article, chapter, or book on teaching, curriculum, or assessment End-of-course evaluation results

Note. The following Cronbach alphas indicates the internal consistency reliability.

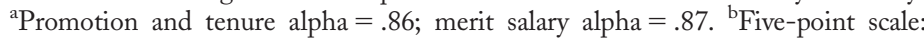
$1=$ not at all, $2=$ slightly, $3=$ moderately, $4=$ a good deal, $5=$ a great deal. ${ }^{\text {CPro- }}$ motion and tenure alpha $=.78 ;$ merit salary alpha $=.83$.
} 
Table 4 Descriptive Statistics of Dependent Variables

\begin{tabular}{lcc}
\hline & \multicolumn{2}{c}{$\begin{array}{c}\text { All faculty } \\
(N=906)\end{array}$} \\
\cline { 2 - 3 } Dependent variables & $M$ & $S D$ \\
\hline Instructional practice: Active learning pedagogy $^{\mathrm{a}}$ & 2.50 & 0.61 \\
Instructional practice: Detailed and frequent feedback $^{\mathrm{a}}$ & 2.92 & 0.74 \\
Instructional practice: Lecture $^{\mathrm{a}}$ & 3.69 & 0.60 \\
Assessment: Activity-based learning $^{\mathrm{b}}$ & 2.17 & 0.87 \\
Assessment: Instructor-centered assessment $^{\mathrm{b}}$ & 2.17 & 0.95 \\
\hline
\end{tabular}

${ }^{\mathrm{a}}$ Four-point scale: $1=$ never, 2 = sometimes, $3=$ often, $4=$ very often. ${ }^{\mathrm{b}}$ Five-point scale: $1=$ not at all, $2=$ slightly, $3=$ moderately, $4=$ very, $5=$ extremely.

Table 5 Dependent Variable Scales with Item Components

Active learning pedagogy scale (alpha $=.70$ )

In this course, ${ }^{\mathrm{a}}$ how often do you use the following instructional approaches? ${ }^{\mathrm{b}}$ Hands-on activities and/or assignments

In-class, small-group learning

Group projects

In-class discussions

Reverse-engineering exercises

Case studies or real-world examples

Detailed and frequent feedback scale (alpha $=.81)$

In this course, ${ }^{a}$ how often do you use the following instructional approaches? ${ }^{\mathrm{b}}$ Frequent feedback to students

Detailed feedback to students

Activity-based learning assessment scale (alpha $=.83$ )

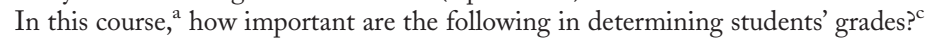

Lab assignments

Presentations

Individual or group written reports

Students' self-assessment of work or progress

Peer assessment (i.e., students provide feedback to one another)

Design projects

Instructor-centered assessment scale (alpha $=.78)$

In this course, ${ }^{a}$ how important are the following in determining students' grades? Class participation

Attendance

Note. The Cronbach's alpha indicates the internal consistency reliability.

${ }^{a}$ Faculty members were asked to report about an undergraduate course that they regularly teach. ${ }^{b}$ Four-point scale: $1=$ never, $2=$ sometimes, $3=$ often, $4=$ very often.

${ }^{\mathrm{c}}$ Five-point scale: 1 = not at all, $2=$ slightly, $3=$ moderately, $4=$ very, $5=$ extremely.

reported on the frequency that they used various practices in an undergraduate course that they regularly teach on a four-point scale, where $1=$ never, $2=$ sometimes, $3=$ often, and $4=$ very often. Both assessment-related dependent variables were scale variables resulting from our 
factor analysis of survey items (activity-based learning; instructor-centered assessment; see Table 5). Faculty members reported on the importance of several activities in determining grades on five-point scales for these variables, where $1=$ not at all, $2=$ slightly, $3=$ moderately, $4=$ very, and $5=$ extremely.

These dependent variables can be characterized as being desirable or less desirable teaching practices, depending on the degree to which they support learning. Three of the variables represent student-centered teaching strategies that the literature suggests promote deep learning and engagement; these strategies include the use of active learning pedagogy, the use of activity-based learning in assessment, and the provision of frequent and detailed feedback to students. We considered lecturing and instructor-centered assessment to be less desirable strategies because they do not aim to stimulate deep learning in students. We recognize that the name of the instructor-centered assessment scale variable may seem counterintuitive because it comprises two items - grading based on class participation and grading based on class attendance - that may not be synonymous in the minds of readers. Some readers may view class participation as a form of active learning and thus a student-centered assessment practice. Yet, in the factor analyses of all items related to assessment practices, these two forms of assessment loaded on a single factor and not on the active learning assessment factor. Individual faculty members in this sample responded in a similar manner to these two items. Basing grades on attendance and class participation may be perceived as measures of "seat time." In our analyses, the variables measuring the use of lecturing and instructor-centered assessment allowed us to investigate our hypothesis that the variables that are positively associated with student-centered practices are negatively associated with instructor-centered ones.

\section{Analytic Procedures}

We used several multiple linear regression analyses to identify possible influences on the use of various teaching practices and assessment strategies; we ran separate linear regressions for each of the five dependent variables. Although the dependent variables are measured on four-point scales, four of the five were created through factor analysis; the resulting values for each scale variable thus include many noninteger values and were treated as continuous variables. The fifth outcome variable is a single item on a four-point scale. However, because we imputed missing data, many values for this variable similarly are nonintegers, and there are 92 unique values for this variable. We thus treated this outcome variable as continuous.

Each of the five regression analyses included all of the control and independent variables. We report standardized coefficients as well as statistical significance for each variable. The standardized coefficient allows for comparisons across variables with different scales (e.g., comparing a coefficient for class size to that of number of hours completing research) to determine the relative importance of each variable in explaining variation in the dependent variable.

\section{Limitations}

We acknowledge that this study has limitations that may influence the conclusions we are able to draw from the results. First, although we studied formal training for teaching during graduate education, we did not assess the impact of teaching assistantships on faculty members' choices of teaching strategies. Teaching assistantship experiences vary significantly by program and institution; some require that graduate teaching assistants undergo formal instruction in teaching while others do not. Variation in instructional choices driven by such experiences cannot be captured with the available independent variables. Second, this study relied on self-reports of teaching behaviors rather than observations. To maximize external 
validity (i.e., generalizability) of our results, we compromised on precision of measurement (McGrath, Martin, \& Kulka, 1982). Since faculty members' identities remained anonymous while they completed the survey, we have no way of verifying their actual behaviors in their classrooms. Our concern is not the truthfulness of faculty responses but rather the variation in how faculty members interpret terms such as collaborative learning and peer feedback (see, for example, discussions by Prince, 2004). In addition, it is possible that respondents interpreted response options somewhat differently. In this regard, it is important to stress that this analysis assessed the relative frequency of the use of student-centered teaching practices between groups of faculty members rather than assessing the absolute frequency of their use. We also acknowledge that it is possible that faculty who sought out graduate training in teaching may have selected institutions where they could engage in more student-centered practices. Finally, because we did not use an experimental design in this study, we can only speculate about causal relationships suggested by our data. For instance, we cannot say that attending engineering education conferences leads to the use of active learning pedagogies. Indeed, it may be the other way around; it could be the case that faculty who use active learning are more likely to attend engineering education conferences because of their established interested in teaching and learning. Although our findings are correlational, our hypotheses have theoretical support from the literature, and we speculate that our results provide additional evidence that certain professional development activities and organizational values contribute to faculty members' decisions about teaching strategies.

\section{Results}

We focus our discussion on the independent variables of interest and do not describe relationships between individual control variables and instructional techniques. Table 6 indicates that, collectively, the control variables account for between $8 \%$ and $23 \%$ of the variance in the use of instructional techniques (Block 1). When graduate training, professional development activities,

Table $6 R$-Squared Values for Blocked Regression Analyses

\begin{tabular}{|c|c|c|c|c|c|}
\hline \multirow[b]{2}{*}{ Variables } & \multicolumn{3}{|c|}{ Student-centered techniques } & \multicolumn{2}{|c|}{$\begin{array}{l}\text { Instructor-centered } \\
\text { techniques }\end{array}$} \\
\hline & $\begin{array}{c}\text { Activity-based } \\
\text { learning } \\
\text { assessment }\end{array}$ & $\begin{array}{c}\text { Active } \\
\text { learning } \\
\text { pedagogy }\end{array}$ & Feedback & $\begin{array}{l}\text { Instructor- } \\
\text { centered } \\
\text { assessment }\end{array}$ & Lecture \\
\hline Block 1: Control variables & 0.23 & 0.16 & 0.09 & 0.10 & 0.08 \\
\hline $\begin{array}{l}\text { Block 2: Controls }+ \text { graduate } \\
\text { training and professional devel- } \\
\text { opment }+ \text { contextual/organi- } \\
\text { zational factors }\end{array}$ & 0.29 & 0.24 & 0.16 & 0.15 & 0.12 \\
\hline
\end{tabular}

Note. Control variables include institutional type, course size and type, faculty gender, race/nationality, tenure status, rank, and discipline. Professional development variables include graduate training to teach and professional development activities such as attending a workshop on teaching, learning, or assessment. Contextual/organizational variables include self-reported time spent on research, perceived weight given to research versus teaching in the department, and perceived emphasis on engineering education research and curriculum enhancement in promotion and tenure and merit salary decisions. 
and contextual variables are included in the regression analyses, the amount of explained variance in the use of each of the instructional techniques ranges from 12\% to 29\% (Block 2).

Graduate student training in teaching $\left(\mathbf{H}_{\mathbf{1}}\right)$ Regression results provided partial support for $\mathrm{H}_{1}$ (Table 7). Participation in a teaching training program in graduate school positively related to faculty members' use of active learning pedagogy, although the effect is small (.08). These findings align with the expectation that exposure to active learning instructional strategies during graduate education would encourage the use of active learning in engineering classrooms. Neither the use of activity-based learning assessment nor providing detailed and frequent feedback to students significantly related to graduate student training. It is possible that such training programs focus on what instructors can do in the classroom to create an engaging environment rather than providing training in how teachers may complete the activity-assessment-feedback loop. Finally, as hypothesized, we found negative relationships between training in graduate school and faculty members' use of instructor-centered techniques, but the relationships were not statistically significant.

Professional development for teaching $\left(\mathbf{H}_{2}\right)$ The type of professional development activity in which faculty members engaged differentially related to their use of student-centered and instructor-centered pedagogical techniques (Table 7). Taking a class or working in industry to enhance knowledge or skills related significantly and positively to two of the three studentcentered techniques, but was not significantly related to the instructor-centered dependent variables. Faculty members who had attended an instructional workshop on teaching, learning, or assessment in the past year reported significantly higher use of activity-based learning assessment and active learning pedagogy. Faculty members who reported making a significant effort to improve teaching reported more frequent use of detailed and frequent feedback to students. This relationship may reflect the fact that providing high-quality, individualized feedback to students requires more faculty time and effort than do pedagogical techniques geared toward the class as a whole. Reading or writing related to the scholarship of teaching also significantly related to several instructional activities. Faculty members who read journals or books on teaching, learning, or assessment as well as those who wrote a paper, article, or chapter on teaching, curriculum, or assessment reported using active learning pedagogies more frequently. The latter group also reported less frequent use of lectures, as might be expected, and greater use of instructor-centered assessment.

In general, we found that professional development opportunities that provide information about teaching and learning significantly and positively related to faculty members' use of some student-centered practices in the classroom and, in a few cases, negatively related to the use of what we categorized as instructor-centered pedagogies. These findings align with expectations that faculty members who engage in professional development activities would also engage in more student-centered teaching practices.

Weight given to research (relative to teaching) $\left(\mathbf{H}_{3}\right)$ We observed mixed support for our hypotheses related to the research orientation of faculty members and their perceptions of the research orientation of their departments (Table 7). As the time spent on research increased, the use of active learning pedagogy increased. This finding was not what we expected; we began with the assumption that as faculty members spend more time on research they spend less time on student-centered teaching and assessment. This finding deserves further investigation, and we take it up in the discussion section that follows.

Perceptions of the weight given to research versus teaching in hiring decisions, promotion and tenure decisions, and merit salary decisions were unrelated to the adoption of student- 


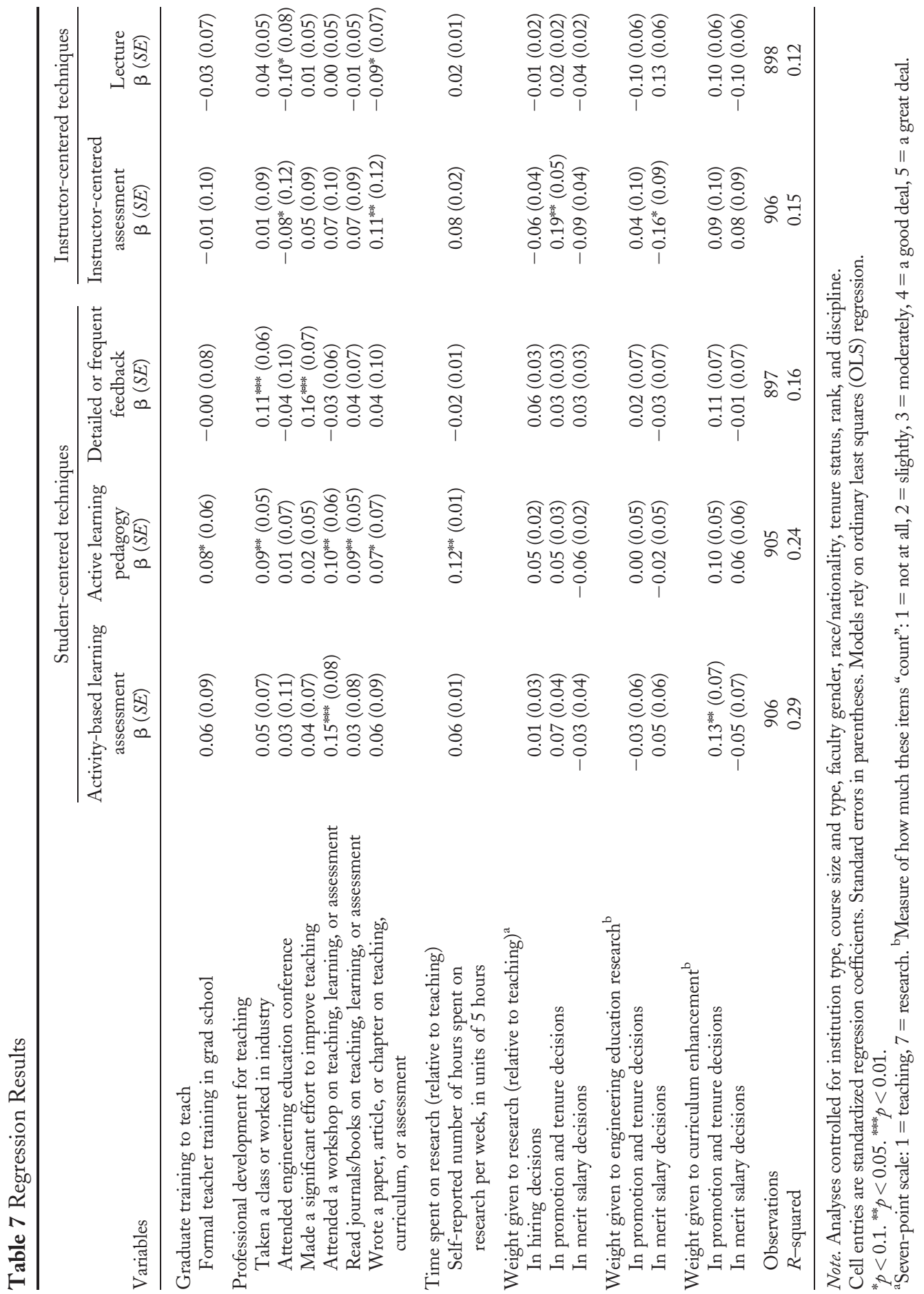


centered pedagogical techniques. Perceptions of faculty rewards were, however, related to the use of instructor-centered assessment strategies; faculty members who believed that their departments' promotion and tenure policies emphasize research more than teaching reported using instructor-centered assessment significantly more often than those who perceived a lesser emphasis on research relative to teaching. This finding is suggestive, however, rather than conclusive. There is a relatively strong relationship between emphasis on research (relative to teaching) in promotion and tenure decisions and the use of instructor-centered teaching practices (.19), but it is the only statistically significant relationship of the 15 relationships we tested for this hypothesis. Additional research may confirm that hiring and merit salary decisions are less likely to influence faculty members' instructional behaviors than promotion and tenure policies that reward activities to improve teaching and learning.

Weight given to engineering education research $\left(\mathbf{H}_{\mathbf{4}}\right)$ Regression results provided little support for our hypothesis about engineering education research; only one of the 10 relationships between instructional strategies and the weight given to engineering education research in the faculty reward system was significant (Table 7). Faculty respondents who perceived that their departments' merit salary decisions placed more value on engineering education research tended to use instructor-centered assessment techniques less often than did those who believed such educational research was less valued in merit salary decisions. In this one instance, departmental values related to instructional practice in the ways one would expect. We identified no statistically significant relationships, however, between the use of studentcentered teaching strategies and the perception that engineering education research is valued in merit salary and tenure decisions. It may be that engaging in engineering education research may have the same impact as engagement in disciplinary research (i.e., it shifts faculty members' time away from day-to-day teaching activities), but we present an alternative explanation in the discussion section.

Weight given to curriculum enhancement $\left(\mathbf{H}_{5}\right)$ We also found only minimal support for our hypothesis that faculty members who perceive curriculum enhancement efforts to be valued in merit salary and promotion and tenure decisions are more likely to use studentcentered pedagogies and less likely to use instructor-centered pedagogies. We found that when faculty believed that curriculum enhancement was valued in promotion and tenure decisions, they were more likely to report using activity-based learning assessment in their courses (Table 7). None of the other pedagogical approaches, either student-centered or instructorcentered, significantly related to perceptions of the value of curriculum enhancement in promotion and tenure. Finally, no instructional practices significantly related to perceptions of the value of curriculum enhancement activities in merit salary decisions. While these findings do not support our hypothesis, they bolster claims that researchers overestimate the influence of reward systems on faculty behavior (O'Meara et al., 2008).

\section{Discussion and Implications}

In this study, we sought to identify factors linked to the use of student-centered teaching and assessment practices among engineering faculty. We examined the role of faculty members' participation in professional development activities (during graduate study and afterward) and departmental contexts on engineering faculty members' use of student-centered teaching and assessment strategies. Although the use of such teaching practices appears to have increased among engineering faculty in recent years (Lattuca et al., 2006) and although 
these practices have been shown to improve student learning and engagement (Prince, 2004), they are not yet the norm in engineering programs (Jamieson \& Lohmann, 2012).

Our analyses indicate that of these potential influences, professional development activities - and, to a lesser extent, training in graduate school - are most strongly linked to the use of student-centered pedagogies. The relationship between graduate training in teaching and the use of active learning pedagogies is quite modest, but this study may have underestimated the strength of the relationship between graduate training in teaching and studentcentered teaching and assessment practices. First, we do not have a measure of participation in teaching assistantships, although we acknowledge that holding such a position does not guarantee that a graduate student has been prepared to teach. Moreover, because of the low levels of participation in any kind of graduate program on teaching among the engineering faculty in our nationally representative sample, we created a dichotomous variable for graduate training to teach. This variable combined all the types of experiences related to teaching in graduate school included on our survey, no matter their nature or duration: attended a program for graduate students on how to teach, took course(s) in college teaching, and completed a teaching certificate during graduate program. We compared participation in any of these experiences with participation in none of these. Thus, respondents who had perhaps attended a one-hour orientation before serving as a graduate teaching assistant were combined with those who completed a multicourse certificate program while in their doctoral programs. It stands to reason that a single experience or one of short duration will have less influence on individuals' beliefs about teaching and learning and their capacity to use pedagogies such as active and collaborative learning. Combining all of these responses is thus likely to dilute the effects of longer, and potentially more formative, experiences. Additional research is needed to understand the effects of these kinds of graduate student teaching programs on faculty members' use of student-centered practices. As more universities require training for teaching assistants and promote completion of teaching certificates and other extended experiences for future faculty, researchers should also explore the influence of voluntary versus mandatory participation in such programs on teaching practices. It is possible that graduate students who choose to attend such programs are predisposed to teaching in general and to student-centered teaching specifically.

The finding that graduate training in teaching relates to the use of student-centered teaching practice has both scholarly and practical importance. There has been little rigorous study of how participation in programs that prepare graduate students for their teaching roles shapes instructional choices. The only large-scale study of this subject asked participants about their perceived readiness to teach but not about their teaching behaviors (Golde \& Dore, 2001). Our study provides some of the first evidence that graduate training in teaching is linked to the use of student-centered teaching strategies. Advocates of programs that prepare future faculty for their teaching (and other) professional roles will be heartened by our finding, since it supports the argument that these programs may benefit not only graduate students, who will enter the classroom better prepared to use a variety of teaching methods, but also the students that these future faculty teach.

We also found that a variety of professional development activities positively relate to engineering faculty members' use of student-centered teaching practices. Specifically, we found that attending a workshop on teaching or assessment also positively related to the use of student-centered teaching practices, in particular the use of active learning pedagogy and activity-based learning assessments such as group presentations and peer and self-assessments. The latter is one of the strongest relationships we found among instructional variables and 
professional development activities. Faculty reports of making "significant efforts" to improve their own teaching related positively to our measure of providing feedback to students; this result may reflect the recognition that giving students frequent and detailed feedback requires a significant time investment. Felder et al. (2011) noted that one of the weaknesses of evaluations of instructional development activities is their general inability to link attendance at a workshop or program to changed teaching behaviors. Self-reports from the faculty who attended the programs are considered suspect. Our findings lend some "third party" support to the findings from such evaluations by showing that student-centered teaching practices relate to professional development focused on teaching and learning. Because our analysis is correlational, however, our findings cannot be considered conclusive.

Our results should also be viewed cautiously in light of evidence that while faculty report they use student-centered teaching practices in the classroom, observational evidence of their teaching often reveals continued reliance on lecture-based, teacher-centered pedagogies (Ebert-May et al., 2011). The findings of Ebert-May et al. (2011) are consistent with those of an observational study of 57 math and science faculty by Hora and Ferrare (2013), who found that lecturing "co-occurred" with more student-centered teaching methods such as demonstrations, working out problems, rhetorical questions, and illustrations and examples. Hora and Ferrare thus concluded that a more complex view of lecturing was needed, since lecturing was sometimes done in concert with interactive teaching methods. They also noted, however, that in their study lecturing most often co-occurred with "receive/memorize" approaches to teaching (p. 248).

Both studies discuss the limitations of self-reports of teaching and have implications for large-scale studies of teaching and learning. First, when it is not possible to include repeated observations of teaching behaviors because of large sample sizes, Hora and Ferrare's findings suggest that researchers should ask faculty members to report their use of a variety of teaching practices rather than limiting them to a single, global assessment of their teaching, as in the study conducted by Ebert-May et al. Permitting respondents to identify multiple teaching strategies allows for the possibility that faculty members employ multiple teaching strategies in a single course. Second, improving self-report measures of teaching clearly should be a priority for researchers engaged in large-scale studies of teaching and learning. Gathering information on the use of a wider array of teaching strategies would permit more finegrained analysis of teaching practices. In addition, surveys should include items that would gather more specific information on how and how often lecture is used, as well as how it may be combined with teaching strategies that are intended to engage students actively in their learning. Since there is some evidence that faculty adapt particular teaching strategies rather than apply them as their creators expect (see Turpen \& Finkelstein, 2009, for a discussion of peer instruction), survey items that assess the fidelity of the application are also advisable.

Our study also found that reading about teaching and learning modestly related to the use of student-centered practices. Interestingly, whereas writing a book, chapter, or paper on curriculum, teaching, or learning positively related to the use of active learning pedagogies, it also positively related to the use of instructor-centered assessment. This finding may point to some ambiguity in our measure of grading on participation and class attendance, which may be a student-centered pedagogy in courses based on small group work (such as capstone design courses) but instructor-centered in larger courses where points are awarded for simply attending class. 
Taking a class or working in industry to improve one's content knowledge or skills also positively related to the use of active learning pedagogies, activity-based learning assessment, and the use of frequent and detailed feedback to students. This finding is not as counterintuitive as it may first appear. In engineering fields, emerging technologies create a dynamic workplace environment that challenges faculty to keep up with recent developments so they can explain or demonstrate them to students. While faculty members' decisions to take classes to improve their content knowledge might be interpreted as contributing to their research capacity or consulting opportunities, our findings show that such professional development activities related to the use of student-centered teaching practices. This finding is consistent with previous research. Clark's (1987) interviews with college and university faculty found that research and teaching activities often merged "in a seamless blend" (p. 70). In an ethnographic study, Colbeck (1998) similarly found that faculty members integrated classroom-oriented teaching and research, and that, in general, the faculty observed for the study combined teaching and research goals about $20 \%$ of the time.

We found modest relationships between departmental environments and teaching and assessment practices. As faculty perceived an increase in the emphasis on research (relative to teaching) in promotion and tenure decisions, the use of instructor-centered assessments also rose. Conversely, when faculty members perceived that curriculum enhancement activities are valued in promotion and tenure, the use of activity-based assessments increased. Although previous research suggests the importance of departmental contexts and reward systems on faculty decision making, our study suggests that these environmental variables may be less strongly related to engineering faculty members' teaching practices than is typically assumed. Our findings suggest that faculty members' decisions to engage in professional development activities to enhance their teaching more consistently related to what they do in the classroom than were perceptions of reward systems.

Our findings support researchers' arguments that making decisions about instructional strategies is a complex process in which a combination of cognitive, sociocultural, and organizational factors interacts to shape teaching behaviors (Lattuca \& Stark, 2009; Oleson \& Hora, 2014). Our findings also align with those from a study of more than 4,500 instructors in the 10-campus University of Hawaii system regarding attitudes towards, and use of, distance learning technologies in their teaching (Johnsrud, Harata, \& Tabata, 2005). The study found that self-assessments of skills and interests dominated the 11 positive influences on participation in distance education. These self-assessments of skills and interests included instructors' beliefs that their technology skills were adequate, that technology was important for conducting their professional work, that technology enhanced their self-image and was compatible with their work style, and that technology was easy to use.

Negative influences on instructors' participation in distance education, surprisingly, included the availability of resources to support distance education and the perception that it was valued by the institution. These findings are consistent with a view of faculty motivation that emphasizes the role of individual interests and self-assessments of competencies, as well as of institutional conditions, in shaping faculty behavior. Both our findings and those of Johnsrud and her colleagues support the claim by O'Meara et al. (2008) that researchers tend to overestimate the role of institutional factors in shaping faculty members' teaching and assessment practices.

Support for the claim made by O'Meara et al. does not mean that institutional cultures and reward systems are unimportant influences on instructional decisions. Hora (2012), Stark, Lowther, Ryan, and Genthon (1988), and others have shown that faculty take local culture, 
policies, and practices into account, as well as the curriculum itself, as they plan and teach their courses. Rather, our findings support calls for complex conceptualizations of the influences on faculty decisions about their work. Future research should explore a comprehensive set of contextual and individual factors - and their interactions - on the decisions engineering faculty make about how to teach particular topics to particular groups of students.

Although our study design does not allow for causal claims, one possible - but not conclusive - explanation for our findings is that professional development for teaching boosts the use of student-centered teaching among engineering faculty. If this is true, engineering departments seeking to increase the use of student-centered instructional and assessment approaches should consider supporting faculty engagement in on- and off-campus professional development activities related to teaching, learning, and assessment. Studies link faculty members' beliefs about education with their course planning behaviors (Scott, Chovanec, \& Young, 1994; Stark et al., 1988) and faculty attitudes toward particular instructional approaches with their use of those instructional approaches (Johnsrud et al., 2005). Our findings may also support the idea that high-quality professional development to enhance the skills of faculty who find active learning pedagogies, for example, congenial may be, on average, a more effective strategy for increasing the use of student-centered classroom practices than emphasizing pedagogical scholarship and curriculum enhancement in reward systems. This approach may also ensure greater fidelity in the implementation of innovative and active learning pedagogies.

\section{Conclusion}

National reports on engineering education recommend professional development programs that prepare future faculty to teach, changes in reward systems, and the creation of more favorable departmental climates to encourage educational improvements. While a multifaceted approach may be needed, this study points to the potential of prioritizing certain professional development activities to yield the desired improvements as well as pursuing longerterm institutional transformation efforts to enhance the teaching orientation of faculty in engineering programs.

\section{Acknowledgments}

This study was supported by a grant from the National Science Foundation (NSF DUE0618712). The opinions expressed here do not reflect the opinions or policies of NSF, and no official endorsement should be inferred. The authors wish to acknowledge the contributions of the members of the research team who participated in various stages of the development of the design, instruments, and databases for this project: Patrick T. Terenzini, Betty J. Harper, Alexander C. Yin, Gul Kremer, Thomas A. Litzinger, Daniel Merson, David C. Perez II, and Hyun Kyoung Ro. India McHale and Travis York also served as graduate research assistants on the project team.

\section{References}

ABET (2013). Engineering Criteria 2000 for 2014-15. Retrieved from http://www.abet. org/uploadedFiles/Accreditation/Accreditation_Step_by_Step/Accreditation_Documents/ Current/2014_-_2015/E001\%2014-15\%20EAC\%20Criteria\%203-13-14(2).pdf

Ambrose, S., \& Norman, M. (2006). Preparing engineering faculty as educators. The Bridge, $36(2), 25-32$. 
Armor, D. J. (1974). Theta reliability and factor scaling. In H. Costner (Ed.). Sociological methodology 1973-1974 (pp. 17-50). San Francisco, CA: Jossey-Bass.

Austin, A. E. (2002). Preparing the next generation of faculty: Graduate schools as socialization to the academic career. Journal of Higher Education, 73(1), 94-122. doi:10.1353/ jhe.2002.0001

Austin, A. E., \& Wulff, D. H. (2004). The challenge to prepare the next generation of faculty. In D. Wulff \& A. Austin (Eds.), Paths to the professoriate: Strategies for enriching the preparation of future faculty (pp. 3-16). San Francisco, CA: Jossey-Bass.

Baldwin, R. G., \& Chronister, J. L. (2001). Teaching without tenure: Policies and practices for a new era. Baltimore, MD: The Johns Hopkins University Press.

Blackburn, R. T., \& Lawrence, J. H. (1995). Faculty at work: Motivation, expectation, satisfaction. Baltimore, MD: The Johns Hopkins University Press.

Bransford, J. D., Brown, A. L., \& Cocking, R. R. (1999). How people learn: Brain, mind, experience, and school. Washington, DC: National Academy Press.

Clark, B. R. (1987). The academic life: Small worlds, different worms. Princeton, NJ: Carnegie Foundation for the Advancement of Teaching.

Colbeck, C. L. (1998). Merging in a seamless blend: How faculty integrate teaching and research. Journal of Higher Education, 69(6), 647-671.

Connelly, M. R., \& Millar, S. B. (2006). Using workshops to improve instruction in STEM courses. Metropolitan Universities, 17(4), 53-65.

Dempster, A. P., Laird, N. M., \& Rubin, D. B. (1977). Maximum likelihood from incomplete data via the EM algorithm. Journal of the Royal Statistical Society, Series B, 39, 1-38.

Dickie, L. O., Dedic, H., Rosenfield, S., Rosenfield, E., \& Simon, R. A. (2006). Success and persistence in science: The influence of classroom climate. Arxiv preprint physics/ 0610243. Retrieved from http://arxiv.org/pdf/physics/0610243.pdf

Ebert-May, D., Derting, T. L., Hodder, J., Momsen, J. L., Long, T. M., \& Jardeleza, S. E. (2011). What we say is not what we do: Effective evaluation professional development programs. BioScience, 61(7), 550-558.

Fairweather, J. S. (1996). Faculty work and public trust: Restoring the value of teaching and public service in American academic life. Boston, MA: Allyn \& Bacon.

Felder, R. M, \& Brent, R. (2010). The National Effective Teaching Institute: Assessment of impact and implications for faculty development. Journal of Engineering Education, 99(2), 121-34.

Felder, R. M., Brent, R., \& Prince, M. J. (2011). Engineering instructional development: Programs, best practices, and recommendations. Journal of Engineering Education, 100 (1), 89-122.

Golde, C. M., \& Dore, T. M. (2001). At cross purposes: What the experiences of doctoral students reveal about doctoral education. Retrieved from http://phdsurvey.org/ report\%20final.pdf

Graham, J. W. (2009). Missing data: Making it work in the real world. Annual Review of Psychology, 60, 549-576.

Hammrich, P. L. (1996). The impact of teaching assistants' conceptions on college science teaching. Journal of Graduate Teaching Assistant Development, 3, 109-117.

Hammrich, P. L. (2001). Preparing graduate teaching assistants to assist biology faculty. Journal of Science Teacher Education, 12, 67-82.

Hora, M. T. (2012). Organizational factors and instructional decision-making: A cognitive perspective. Review of Higher Education, 35(2), 207-235. 
Hora, M. T., \& Ferrare, J. J. (2013). Instructional systems of practice: A multidimensional analysis of math and science undergraduate course planning and college teaching. Journal of the Learning Sciences, 22, 212-257. doi: 10.1080/10508406.2012.729767

Huang, Y. M, Yellin, J. M. H., \& Turns, J. (2005). Future engineering faculty: How do they think about teaching? Paper presented at the 35th Annual meeting of the ASEE/IEEE Frontiers in Education Conference, Indianapolis, IN. doi:10.1109/FIE.2005.1611942

Huba, M. E., \& Freed, J. E. (2000). Learner-centered assessment on college campuses: Shifting the focus from teaching to learning. Boston, MA: Allyn \& Bacon.

Ishikawa, C. M., Potter, G.R., Blickenstaff, J. A., De Leone, C. J., Castori, P., \& Potter, W. H. (2000). Changes in Physics 7 graduate student instructors' conceptions of teaching and learning following a professional development program. Paper presented at the meeting of the National Association for Research in Science Teaching, New Orleans, LA.

Jamieson, L. H., \& Lohmann, J. R. (2012). Innovation with impact: Creating a culture for scholarly and systematic innovation in engineering education. Washington, DC: American Society for Engineering Education. Retrieved from http://www.asee.org/about-us/theorganization/advisory-committees/Innovation-with-Impact

Johnson, D. W., Johnson, R. T., \& Smith, K. A. (1998). Active learning: Cooperation in the college classroom. Edina, MN: Interaction Book Company.

Johnsrud, L. K., Harada, V. H., \& Tabata, L. N. (2005). Faculty attitude, adoption, and application of technology in higher education: Implications for distance education policy. Honolulu, Hawaii: Hawaii Educational Policy Center.

Kuh, G. D., Kinzie, J., Shuh, J. H., and Whitt, E. J., and Associates (2005). Student success in college: Creating conditions that matter. San Francisco: Jossey-Bass.

Lattuca, L. R., \& Stark, J. S. (2009). Shaping the college curriculum: Academic plans in context. San Francisco, CA: Jossey-Bass.

Lattuca, L. R., Terenzini, P. T., \& Volkwein, J. F. (2006). Engineering change: A study of the impact of EC2000. Baltimore, MD: ABET.

Lattuca, L. R., Yin, A. C., \& McHale, I. M. (2010). Influences on engineering faculty members' teaching and beliefs about teaching. Research paper presented at the 35th Annual Meeting of the Association for the Study of Higher Education, Indianapolis, IN.

Lindblom-Ylanne, S., Trigwell, K., Nevgi, A., \& Ashwin, P. (2006). How approaches to teaching are affected by discipline and teaching context. Studies in Higher Education, 31(3), 285-298.

Lindholm, J. A., Szelenyi, K., Hurtado, S., \& Korn, WS (2005). The American college teacher: National norms for the 2004-2005 HERI faculty survey. Los Angeles, CA: Higher Education Research Institute, UCLA.

Lueddeke, G. R. (2003). Professionalising teaching practice in higher education: A study of disciplinary variation and 'teaching-scholarship.' Studies in Higher Education, 28(2), 213228.

Luft, J. A., Kurdziel, J. P., Roehrig, G. H., \& Turner, J. (2004). Growing a garden without water: Graduate teaching assistants in introductory science laboratories at a doctoral/ research university. Journal of Research in Science Teaching, 41(3), 211-233.

McGrath, J. E., Martin, J., \& Kulka, R. A. (1982). Judgment calls in research. Beverly Hills, CA: Sage.

National Academy of Engineering. (2004). The engineer of 2020: Visions of engineering in the new century. Washington, DC: National Academies Press. 
National Academy of Engineering. (2005). Educating the engineer of 2020: Adapting engineering education to the new century. Washington, DC: National Academies Press.

National Academy of Engineering. (2008). Grand challenges in engineering. Washington, DC: National Academy of Engineering. Retrieved from http://www.engineeringchall enges.org

National Association of Graduate-Professional Students. (2001). 2000 National doctoral program survey results. Retrieved from http://www.nagps.org/survey2000

Nelson-Laird, T. F., Shoup, R., Kuh, G. D., \& Schwarz, M. J. (2008). The effects of discipline on deep approaches to student learning and college outcomes. Research in Higher Education, 49, 469-494.

Oleson, A., \& Hora, M. T. (2014). Teaching the way they were taught? Revisiting the sources of teaching knowledge and the role of prior experience in shaping faculty teaching practices. Higher Education, 68(1), 29-45. doi:10.1007/s10734-013-9678-9

O'Meara, K., Terosky, A.L., \& Neumann, A. (2008). Faculty careers and work lives: A professional growth perspective. ASHE Higher Education Report, 34(3). San Francisco, CA: Jossey-Bass.

Pfund, C., Miller, S., Brenner, K., Bruns, P., Chang, A., Ebert-May, D., . . . Handelsman, J. (2009). Summer institute to improve university science teaching. Science, 324, 470-471.

Pinder-Grover, T. (2013). Active learning in engineering: Perspectives from graduate student instructors. Proceedings of the 120th Annual Conference of the American Society for Engineering Education, Atlanta, GA.

Prince, M. J. (2004). Does active learning work? A review of the research. Journal of Engineering Education, 93(3), 223-231.

Prosser, M., \& Trigwell, K. (1999). Understanding learning and teaching: The experience in higher education. Buckingham, UK: Open University Press.

Schuster, J. H., \& Finkelstein, M. J. (2006). The American faculty: The restructuring of academic work and careers. Baltimore, MD: The Johns Hopkins University Press.

Scott, S. M., Chovanec, D. M., \& Young, B. (1994). Philosophy-in-action in university teaching. Canadian Journal of Higher Education, 24(5), 1-25.

Sheppard, S. D., Macatangay, K., Colby, A., \& Sullivan, W. (2009). Educating engineers: Designing for the future of the field. San Francisco, CA: Jossey-Bass.

Slavin, R. E. (1995). Cooperative learning: Theory, research, and practice (2nd ed.). Boston, MA: Allyn \& Bacon.

Smart, J. C., \& Ethington, C. A. (1995). Disciplinary and institutional differences in undergraduate education goals. New Directions in Teaching and Learning, 64, 49-57.

Smart, J. C., Feldman, K. A., \& Ethington, C. A. (2000). Academic disciplines: Holland's theory and the study of college students and faculty. Nashville, TN: Vanderbilt University Press.

Sorcinelli, M. (1991). Research findings on the seven principles. New Directions in Teaching and Learning, 47, 13-25.

Stark, J. S., Lowther, M. A., Bentley, R. J., Ryan, M. P., Martens, G. G., Genthon, M. L., \& others. (1990). Planning introductory college courses: Influences on faculty. Ann Arbor, MI: University of Michigan, National Center for Research to Improve Postsecondary Teaching and Learning. (ERIC Document Reproduction Service No. ED330277).

Stark, J. S., Lowther, M. A., Ryan, M. P., \& Genthon, M. (1988). Faculty reflect on course planning. Research in Higher Education, 29, 219-240. 
Tanner, K., \& Allen, D. (2006). Approaches to biology teaching and learning: On integrating pedagogical training into the graduate experiences of future science faculty. CBE Life Sciences Education, 5(1), 1-6.

Trigwell, K. (2002). Approaches to teaching design subjects: A quantitative analysis. Art, Design E Communication in Higher Education, 1(2), 69-80.

Turpen, D., \& Finkelstein, N. D. (2009). Not all interactive engagement is the same: Variations in physics professors' implementation of peer instruction. Physical Review Special TopicsPhysics Education Research, 5, 1-18. doi:http://dx.doi.org/10.1103/PhysRevSTPER.5.020101

Walczyk, J. J., \& Ramsey, L. L. (2003). Use of learner centered instruction in college science and mathematics classrooms. Journal of Research in Science Teaching, 40(6), 566-584.

\section{Authors}

Lisa R. Lattuca is a professor of higher education at the Center for the Study of Higher and Postsecondary Education at the University of Michigan, 610 E. University Ave., Ann Arbor, MI, 48109; 1latt@umich.edu.

Inger Bergom is a doctoral candidate in higher education at the Center for the Study of Higher and Postsecondary Education at the University of Michigan, 610 E. University Ave., Ann Arbor, MI, 48109; inbe@umich.edu.

David B. Knight is an assistant professor of engineering education at Virginia Tech, 614 McBryde Hall, 225 Stanger Street, Blacksburg, VA, 24061; davidknight@vt.edu. 